\title{
O conceito de formação continuada dos professores de Ladário, Mato Grosso do Sul, e o totalitarismo da razão instrumental ${ }^{1}$
}

\author{
Crisley Monteiro de Monteiro², Isabella Fernanda Ferreira ${ }^{3}$
}

\begin{abstract}
Resumo
O Programa Nacional de Alfabetização pela Idade Certa (PNAIC) é uma proposta do Governo Federal, juntamente com os estados e municípios do Brasil e tem como objetivo alfabetizar crianças até $\circ 3^{\circ}$ ano do ensino fundamental. Esse programa se subdivide em quatro eixos: formação continuada; materiais didáticos; avaliação sistemática e gestão; mobilização e controle social. Todavia, concentramo-nos no eixo formação continuada com o propósito de analisar qual a concepção dos professores de uma escola em Ladário, Mato Grosso do Sul, participantes do PNAIC, com relação à formação continuada apresentada pelo programa. Com essa finalidade utilizamos como metodologia o estudo de caso com entrevista semiestruturada e, como referencial, a Teoria Crítica. Concluímos que os professores de Ladário veem a formação continuada do PNAIC como um auxílio para complementar suas práticas pedagógicas, e em nenhum momento se posicionam criticamente sobre as determinações. Detectamos, então, na fala desses sujeitos, a totalização da razão instrumental, visto que não discutem as orientações, apenas as executam.
\end{abstract}

\section{Palavras-chave}

Formação Continuada. PNAIC. Teoria Crítica.

1. Este artigo é um dos produtos científicos desenvolvidos como decorrência da pesquisa que originou a dissertação de mestrado em Educação Social do Programa de Pós-graduação em Educação da Universidade Federal de Mato Grosso do Sul, Campus do Pantanal, intitulada "As concepções dos professores de uma escola de Ladário/MS sobre as ações do Pacto Nacional pela Alfabetização na Idade Certa na perspectiva da teoria crítica".

2. Mestre em Educação Social pela Universidade Federal de Mato Grosso do Sul, Brasil; professora da rede municipal de ensino de Corumbá, Mato Grosso do Sul, Brasil. E-mail: crisleym.olart@gmail.com.

3. Doutora em Educação pela Universidade Estadual Paulista "Júlio de Mesquita Filho", Campus de Araraquara, São Paulo, Brasil; professora adjunta III da Universidade Federal de Mato Grosso do Sul, Brasil; docente permanente do Programa de Pós-graduação em Educação no Campus do Pantanal; docente colaboradora no Programa de Pós-graduação em Educação no Campus de Campo Grande. E-mail: bella.fernandaferreira@gmail.com. 


\title{
The concept of continuing professional education in Ladário, State of Mato Grosso do Sul, Brazil, and the totalitarianism of instrumental reason*
}

\author{
Crisley Monteiro de Monteiro ${ }^{* *}$, Isabella Fernanda Ferreira***
}

\begin{abstract}
The National Pact for Literacy at the Right Age (PNAIC) is proposed by the Federal Government, along with the states and municipalities in Brazil. It aims at teaching children to read and write due the third year of elementary school. The program is divided into four axes: continuing education; teaching materials; systematic assessment and management; mobilization and social control. In this paper, we focused on continuing education, with the purpose of analyzing the concept teachers from a school in Ladário, State of Mato Grosso do Sul, Brazil, have, regarding the way the program approaches continuing education. The teachers participate in the PNAIC. The methodology adopted was case study, with semi-structured interviews. The theoretical basis came from the Critical Theory. We concluded that the teachers we interviewed see PNAIC's continuing education as an aid to complement their pedagogical practices. At no time do they exhibit a critical position towards the determinations. We thus observed, in their speech, the totalization of instrumental reason, as they don't discuss the guidelines - they just follow them.
\end{abstract}

\section{Keywords}

Continuing Education. PNAIC. Critical Theory.

\footnotetext{
* Master in Social Education, Federal University of Mato Grosso do Sul, Brazil; municipal teacher of Corumbá, State of Mato Grosso do Sul, Brazil. E-mail: crisleym.olart@gmail.com.

** PhD in Education, São Paulo State University “Júlio Mesquita Filho", Campus Araraquara, State of São Paulo, Brazil; professor assistant at the Federal University of Mato Grosso do Sul, Brazil; permanent professor in the Post-Graduate Program in Education at Campus Pantanal; assistant professor in the Pos-Graduated Program in Education at Campus Campo Grande. E-mail: bella.fernandaferreira@gmail.com.
} 


\section{Introdução}

Neste artigo, apresentamos as concepções dos professores de uma escola de Ladário, Mato Grosso do Sul, com relação ao eixo "Formação Continuada" do Programa Nacional de Alfabetização pela Idade Certa. Inicialmente torna-se importante sabermos que o PNAIC é um compromisso formal e solidário assumido pelos governos Federal, Distrito Federal, Estados e municípios brasileiros, para assegurar que todas as crianças estejam alfabetizadas até no máximo ao $3^{\circ}$ ano do ensino fundamental em escolas rurais e urbanas (BRASILa, 2017, p. 7). Esse compromisso instituiu-se no dia 4 de julho de 2012, pela portaria 867, assegurada no Decreto no 6.094, de 24 de abril de 2007. Os alunos devem passar por exames periódicos para conferir os resultados alcançados. A investigação através dos professores participantes do PNAIC se deu pela razão do programa referido ser reconhecido como formação continuada e por ter um grande número de participantes.

Outro documento importantíssimo é a Base Nacional Comum Curricular (BNCC) homologada pelo Ministro da Educação, José Mendonça Filho, no dia 20 de dezembro de 2017. O BNCC torna-se um documento normativo que tem como finalidade definir um conjunto de normas progressivas de aprendizagens essenciais para o aluno, de maneira que assegure seus direitos de aprendizagem e desenvolvimento durante a educação básica, como exigido pelo Plano Nacional de Educação (PNE). Na BNCC encontramos a exigência de que:

Nos dois primeiros anos do Ensino Fundamental, a ação pedagógica deve ter como foco a alfabetização, a fim de garantir amplas oportunidades para que os alunos se apropriem do sistema de escrita alfabética de modo articulado ao desenvolvimento de outras habilidades de leitura e de escrita e ao seu envolvimento em práticas diversificadas de letramentos. (BRASILb, 2017, p. 57).
Vemos que com a exigência de alfabetizar o aluno no ciclo correto, há uma preocupação quanto à formação desse professor e que função eleterá no desenvolvimento dessa criança. Diante disso, veremos neste artigo qual a concepção dos professores de Ladário-MS, quanto à formação continuada oferecida pelo PNAIC.

Quanto ao procedimento empírico do artigo, realizamos entrevistas com professores de 1a, 2 ${ }^{a}$ e $3^{\underline{a}}$ séries de uma escola de Ladário MS, utilizando o gravador como instrumento de coleta. Aplicamos questionário semiestruturado individual, para conhecer as concepções dos professores no tocante ao PNAIC e também saber a sua concepção, com relação à formação continuada. Sobre os elementos conceituais deste artigo para análise, elegemos Theodor Adorno para subsidiar nossas reflexões. O objetivo traçado para a realização do trabalho foi o de analisar a concepção dos professores de uma escola em Ladário-MS sobre a implantação do PNAIC, especificamente no que se refere à formação continuada na organização do seu trabalho docente. A partir da coleta dos dados - entrevistas - problematizamos os resultados, sob a perspectiva da Escola de Frankfurt. A partir desse contato, investigamos a concepção de formação continuada no entendimento dos professores que fizeram parte do Programa PNAIC no município de Ladário no período de 2015. A partir desse posicionamento, agregamos informações detalhadas e sistemáticas sobre o tema apresentado. O tipo de pesquisa eleito para atingir os objetivos deste trabalho foi o estudo de caso:

O estudo de caso é próprio para a construção de uma investigação empírica que pesquisa fenômenos dentro de seu contexto real pesquisa naturalística - com pouco controle do pesquisador sobre eventos e manifestações do fenômeno. Sustentada por uma plataforma 
teórica, reúne o maior número possível de informações, em função das questões e proposições orientadoras do estudo, por meio de diferentes técnicas de levantamento de informações, dados e evidências. Como se sabe, a triangulação de informações, dados e evidências garante a confiabilidade e a validade dos achados do estudo. Busca-se, criativamente, apreender a totalidade de uma situação - identificar e analisar a multiplicidade de dimensões que envolvem o caso - e, de maneira engenhosa, descrever, compreender, discutir e analisar a complexidade de um caso concreto, construindo uma teoria que possa explicá-lo e prevê-lo. (MARTINS, 2008, p. $10)$.

Optamos pela pesquisa do tipo estudo de caso com abordagem qualitativa das entrevistas realizadas, tendo como referencial a Teoria Crítica da Sociedade como fundamento para defender a educação como um meio de resistência à barbárie. Essa teoria realça a importância da consciência emancipatória, assunto que faz parte de um diálogo entre Adorno e Becker, no livro Educação e Emancipação, de Adorno (2005). O autor expõe seus pensamentos sobre diversos temas: educação, cultura, arte, tecnologia, entre outros temas que geram muitas discussões, trazendo à tona a sua preocupação com a barbárie.

Adorno (2005) trata o tema barbárie como referência ao antissemitismo ocorrido nos tempos de Auschwitz, e em sua obra discute a preocupação com a conversão humana ao barbarismo naturalizado de cultura. Então, sustentamos que os seus conceitos contribuíram muito na construção de uma ação pedagógica educacional e de formação social, de reação individual e coletiva, reação através da razão, da cultura, da educação e da arte, além de despertar no sujeito um "olhar" mais crítico daquilo que o rodeia.

Os autores frankfurtianos não criaram uma pedagogia sistêmica e organizada. No entanto, trouxeram à tona contribuições que podem ser efetivadas no fazer pedagógico, com o propósito de formar pessoas emancipadas e estimular a autonomia humana. Pucci (1994) referencia a Teoria Crítica como uma forma de pensarmos em como a educação vem sendo construída:

a Teoria Crítica não se propõe a desenvolver uma teoria educacional específica. Pretende sim, a partir de suas análises sobre os problemas sociais do mundo ocidental, especificamente dos problemas culturais, trazer luzes e enfoques novos à concepção dialética da educação que vem sendo constituída, por muitas mãos e mentes, a partir de Marx. (PUCCI, 1994, p. 54).

Theodor Ludwig Wiesengrund Adorno (1903-1969) nasceu em 11 de setembro de 1903 na cidade de Frankfurt, Alemanha. Formou-se em música pela Escola de Viena e em Filosofia pela Universidade Johann Wolfgang Goethe. Voltou-se aos estudos de estética musical, tornando-se musicólogo e crítico literário.

A frase de Adorno: "que Auschwitz não se repita" tornou-se o imperativo que norteia a educação social, de acordo com o autor Pucci (1994). Na discussão erguida no livro Educação e Emancipação (ADORNO, 2005), vemos a preocupação dele com a originalidade e o fortalecimento do que é anticivilizatório. Esse é um dos problemas principais sobre o qual se dedica a Teoria Crítica: o mesmo processo de explicação que levou a um esperado progresso da técnica e da razão trouxe consigo a inevitável barbárie. A crítica de Adorno tem como alvo a própria racionalidade na tentativa da razão voltar-se para si para reconhecer os seus limites e poder esclarecer-se. Adorno não escreveu especificamente sobre educação escolar ou sobre a prática pedagógica, mas defendia que o poder efetivo contra a repetição de Auschwitz era a conquista da autonomia por parte do educando e o poder para a reflexão e a determinação de não fazer parte na barbárie. Atuar de forma 
heterônoma, aceitando normas e compromissos de submissão, atingindo um grau de "cegueira" à autoridade gera condições para à barbárie. Não confrontar a barbárie é a condição para que tudo aconteça novamente. Para Adorno, a educação pautada pela severidade e pela disciplina extrema é condição propícia para a barbárie. A dureza significa indiferença em relação à dor. E a indiferença é um dos obstáculos à filosofia e à educação emancipatória. O autor atribui grande importância à educação durante a primeira infância, quando as crianças

em geral se identificam com uma figura de pai, portanto, com uma autoridade, interiorizando- a, apropriando-a, para então ficar sabendo, por um processo sempre muito doloroso e marcante, que o pai, a figura paterna, não corresponde ao eu ideal que aprenderam dele, libertando-se assim do mesmo e tornando-se, precisamente por essa via, pessoas emancipadas. Penso que o momento da autoridade seja pressuposto como um momento genético pelo processo da emancipação. (ADORNO, 2005, p. 176).

Interpretamos essa citação como uma analogia à educação: visto que, a partir do momento em que a pessoa se emancipa, há um afastamento daquela ilusão primária de que tudo é perfeito. No caso do exemplo da citação, o pai é um ser perfeito, até que o indivíduo cresce, liberta-se da figura paterna e passa a agir sozinho. Isso ocorre na educação: durante a infância, a educação instrui as crianças com base em determinada ideologia; mais tarde, quando adultos, começam a pensar por si. Esse pensar por si, seguir suas ideias, é um processo de emancipação. No entanto, observemos este comentário de Adorno:

Contudo, o que é peculiar no problema da emancipação, na medida em que esteja efetivamente centrado no complexo pedagógico, é que mesmo na literatura pedagógica não se encontre esta tomada de posição decisiva pela educação para a emancipação, como seria de se pressupor - o que constitui algo verdadeiramente assustador e muito nítido. Com o auxílio de amigos a companheiros li um pouco a literatura pedagógica acerca da temática da emancipação. Mas, no lugar de emancipação, encontramos um conceito guarnecido nos termos de uma ontologia existencial de autoridade, de compromisso, ou outras abominações que sabotam o conceito de emancipação atuando assim não só de modo implícito, mas explicitamente contra os pressupostos de uma democracia. Em minha opinião essas coisas deveriam ser expostas e apresentadas de modo mais acessível, tal é o mofo que continua envolvendo na Alemanha até mesmo uma questão aparentemente tão pertinente ao plano do espírito como a emancipação. (ADORNO, 2005, p. 171-172).

Adorno contesta o caráter emancipatório apresentado pela via educacional porque estão atreladas a autoridades e abominações que acabam se chocando com a verdadeira democracia, o que converte a educação em barbarismo. Outro aspecto que o autor apresenta é o processo de esclarecimento da população, aquele que libertaria, emanciparia, que seria um processo abrangente e geral, que criaria um clima cultural e social e que seria um empecilho para a repetição da barbárie, ele não ocorre devido a esse trajeto de instrução. É nesse contexto que Adorno critica a tese que aponta para a necessidade de recuperar a autoridade. Explicita que, se uma pessoa não consegue reconhecer seu próprio "eu", ou não consegue se representar e vive em constantes mudanças e adaptações, não sendo uma pessoa emancipada, comoteráautoridade sobre o outro?

Penso que o momento da autoridade seja pressuposto como um momento genético pelo processo da emancipação. Mas de maneira alguma isto deve possibilitar o mau uso de glorificar e conservar esta etapa, e quando isto ocorre os resultados não serão apenas mutilações psicológicas, mas justamente aqueles fenômenos do estado de menoridade, no sentido da idiotia sintética 
que hoje constatamos em todos os cantos e paragens. (ADORNO, 2005, p. 176).

Sob a perspectiva de Adorno, a primeira infância assume um papel essencial na construção e formação do indivíduo. Para ele é por meio da criança que se incute o pensamento crítico e autônomo, ou seja, devese intencionar o desenvolvimento de um sujeito emancipado, longe das pressões psicológicas e obrigações impostas, para que não cresça um sujeito com sintomas de menoridade, que reproduz tudo o que sofreu na infância, através de seus preceptores. Adorno explica que a formação do caráter do indivíduo ocorre durante a primeira infância. O processo civilizatório gera uma pressão e um sentimento de claustrofobia que é acentuado em um mundo administrado. Para tentar superar isso, ressalta que a violência é usada como uma das formas para se tentar concretizar tal fuga da civilização, mas o ato acaba remetendo à própria barbárie. Evitaríamos a violência se formássemos pessoas, através da educação, que se voltassem para a contradição e a resistência:

Tenho a impressão de que, por mais que isto seja almejável, tudo ainda se dá excessivamente no âmbito institucional, sobretudo da escola. Mesmo correndo o risco de ser taxado de filósofo, o que, afinal, sou, diria que a figura em que a emancipação se concretiza hoje em dia, e que não pode ser pressuposta sem mais nem menos, uma vez que ainda precisa ser elaborada em todos, mas realmente em todos os planos de nossa vida, e que, portanto, a única concretização efetiva da emancipação consiste em que aquelas poucas pessoas interessadas nesta direção orientem toda a sua energia para que a educação seja uma educação para a contradição e para a resistência. (ADORNO, 2005, p. 182).

Considerando as análises de Adorno sobre a formação, nos propomos, aqui, apresentar a compreensão dos professores de uma escola da rede municipal de ensino da cidade de Ladário, em Mato Grosso do Sul, sobre a formação continuada do programa PNAIC.

\section{0 totalitarismo da razão instrumental: problematizando o conceito de formação continuada aos professores de Ladário, Mato Grosso do Sul}

\footnotetext{
"Mas de nada serve agora", pensou a pobre Alice, "fingir que sou duas pessoas!"

Porque tudo o que sobrou de mim mesma é pouco até para ser uma só pessoa respeitável!

(Lewis Carroll, Alice no País das Maravilhas, 1894, p. 12).
}

Dialogamos com as categorias de análise: totalitarismo da razão instrumental, coisificação e formação, segundo a Teoria Crítica, para analisarmos as falas dos sujeitos entrevistados com relação à compreensão do eixo formação continuada do PNAIC.

O totalitarismo da razão instrumental é um tema tratado por Max Horkheimer, juntamente com Adorno. Conceitualmente, a razão instrumental é a maneira como os procedimentos racionais são instrumentalizados. Lemos sobre a razão instrumental no texto Dialética do Esclarecimento, no qual Adorno e Horkheimer, utilizando o personagem Ulisses da obra Odisseia, apresentam-no como uma figura racional e esclarecida no enredo da trama. Nesse sentido, Silva (2015, p. 55) comenta em sua dissertação:

Pode-se dizer que o herói da Odisseia é entendido pelos autores como "racional e esclarecido" no sentido de que ele possui um comportamento orientado racionalmente a partir de uma meta, de um objetivo préestabelecido, qual seja, retornar para casa. Para cumprir seu objetivo, Ulisses precisa se autopreservar e, dessa forma, segundo Adorno e Horkheimer, "o recurso do eu para sair vencedor das aventuras: perder-se para se conservar, é a astúcia". Nesse sentido, é 
possível indicar os momentos dessa singular astúcia: nos encontros com as potências míticas, Ulisses renuncia à sua identidade no episódio dos Ciclopes, à sua liberdade no encontro com as Sereias e, ainda, ao seu próprio prazer no episódio de Circe e dos comedores de Lótus. Desse modo, Ulisses, se é legítimo dizer, cumpre de forma integral o programa do esclarecimento, pois busca não apenas preservar-se das ameaças da natureza, mas também, controlá-las.

Vemos que Ulisses precisa "perder-se para se conservar". O personagem necessita da conservação de si e do controle das forças naturais e místicas para sobreviver. Para isso, precisa controlar a sua natureza humana. Ulisses, para controlar a natureza externa, reprime-se, como forma de sacrifício. Silva (2015, p. 58) acrescenta:

Em consequência, é possível afirmar que o processo civilizatório, do qual a narrativa de Ulisses é utilizada pelos autores como modelo alegórico, desencadeia-se por meio de um ato de violência do homem contra a natureza e contra o próprio homem. Assim, o desenvolvimento da ciência e a manipulação técnica ligam-se de forma inextrincável à dominação da natureza e, por conseguinte, à violência introjetada dos homens sobre os homens, isto é, à violência do sujeito sobre sua própria natureza. Em última instância, na formulação dos autores, "a história da civilização é a história da introversão do sacrifício. Ou por outra, a história da renúncia". Nesse sentido, a autoafirmação do sujeito se dá via essa introversão do sacrifício.

É no texto da Odisseia que Adorno e Horkheimer asseveram que o sujeito nega a si mesmo, não porque sente desejo, mas para se autoconservar, como confirma Silva (2015, p. 59):

De todo modo, será a partir do estudo da Odisseia que se desenvolverá a tese de que a emergência do sujeito se dá com a dominação da sua natureza interna, isto é, pode-se dizer, com o controle do indivíduo sobre o amorfo em si mesmo. Nesse sentido, a autoafirmação do sujeito será entendida, também, como autodenegação. Além disso, o esforço do eu para se autoconservar e se afirmar relaciona-se com a racionalidade desdobrada historicamente como instrumental.

Adorno e Horkheimer chamam de razão instrumental quando o sujeito deixa a si mesmo, aquilo que ele é interiormente, tornando-se um sujeito amorfo na intenção de se autoconservar. Até mesmo a ciência voltada para o experimental, para o descobrir, torna-se algo manipulável, com o intuito de alcançar um fim determinado pelo sujeito, ou seja, alcançar o objetivo estipulado por ele. Para atingir esse objetivo, usa de todos os instrumentos possíveis. Há uma manipulação da ciência para determinar um fim. Adorno e Horkheimer pontuam: "No trajeto para a ciência moderna, os homens renunciaram ao sentido e substituíram o conceito pela fórmula, a causa pela regra e pela probabilidade" (ADORNO; HORKHEIMER, 1991, p. 21). Os autores acreditam que houve um avanço da ciência e da técnica, que dominaram a modernidade para atingir um determinado fim. De certa maneira, ambas têm objetivos implícitos no âmbito da manipulação e do interesse e distinguem-se como práticas instrumentais. Evangelista (2003, p. 5), sobre a razão instrumental, escreve que:

Recusando tudo o que não se enquadra nos critérios de cálculo e utilidade, a ciência moderna positivista busca o método para trabalhar o emaranhado do mundo factual a ser ordenado, classificado, unificado pela lógica formal e traduzido pela matemática e, dessa forma, permite a explicação, a previsão e o controle.

A ciência passou a utilizar da matemática como forma de ordenar e classificar. Tudo passou a ser separado por segmentos unificados; o ser humano passou a ser classificado como mercadoriadominadapelomercado. Noentanto, só há um meio de o ser humano romper com esse rótulo de mercadoria, ou seja, tornando- 
se um sujeito esclarecido e deixando de ser um produto coisificado, de acordo com os autores:

O preço da dominação não é meramente a alienação dos homens com relação aos objetos dominados; com a coisificação do espírito, as próprias relações dos homens foram enfeitiçadas, inclusive as relações de cada indivíduo consigo mesmo. Ele se reduz a um ponto nodal das reações e funções convencionais que se esperam dele como algo objetivo. $\mathrm{O}$ animismo havia dotado a coisa de uma alma, o industrialismo coisifica as almas. O aparelho econômico, antes mesmo do planejamento total, já provê espontaneamente as mercadorias dos valores que decidem sobre o comportamento dos homens. A partir do momento em que as mercadorias, com o fim do livre intercâmbio, perderam todas suas qualidades econômicas salvo seu carácter de fetiche, este se espalhou como uma paralisia sobre a vida da sociedade em todos os seus aspectos. As inúmeras agências da produção em massa e da cultura por ela criada servem para inculcar no indivíduo os comportamentos normalizados como os únicos naturais, decentes, racionais. De agora em diante, ele só se determina como coisa, como elemento estatístico, como success or failure. Seu padrão é a autoconservação, a assemelhação bem ou malsucedida à objetividade da sua função e aos modelos colocados para ela. (ADORNO; HORKHEIMER, 1991, p. 31-32).

Com a coisificação, o ser humano perdeu a maneira de se relacionar, passando a ter relações por interesses. A dominação, então, não é sobre a alienação humana - é sobre aquilo que o sujeito deseja ter. Assim, a cultura massificada produz comportamentos e normas padronizadas, hipnotizando diariamente $\mathrm{O}$ sujeito, que passa a vê-las como naturais. O sujeito segue as ordens do mercado, a fim de que o satisfaça, e pratica ações e reações que agradem o mercado. Evangelista (2003, p. 7) pontua:

Denunciando assim a impossibilidade de realização do ideal emancipador do esclarecimento nos quadros do industrialismo, os autores acrescentam à vinculação desse ideal ao domínio da natureza uma outra razão. Por ela, esse domínio resulta também no domínio dos homens que, como o pensamento, são também coisificados. O caráter fetichista da mercadoria, na sociedade regida pela troca, espalha-se, tal qual a razão instrumental, por todos os espaços sociais, assim como nos comportamentos dos indivíduos.

A partir do momento em que o sujeito deixa de ser esclarecido, torna-se um fetichista, capaz de trocar o seu comportamento, suas ações e seu corpo por algum bem do seu interesse. Não importa a que está se submetendo para agradar o seu "dono", para receber algo em troca - isso acaba se tornando uma razão instrumental. Adorno acredita que o sujeito deixa de ser emancipado e deseja ser tutelado, pois abandona as suas responsabilidades. Há uma urgência de que o sujeito se emancipe, tornando-se esclarecido, pois o esclarecimento e a formação estão unidos no desenvolvimento do sujeito emancipado. Desta maneira: "Educar, esclarecer, formar e emancipar são conceitos que se aglutinam em um mesmo projeto, a promoção do homem como agente de sua história, não como mero espectador" (BANDEIRA, 2016, p. 5). Voltemos então à palavra "formação" que vem de bildung, termo alemão muito usado no período Iluminista, principalmente por pensadores como Kant e Hegel. A tradução de bild é forma, e ung "assinala o processo segundo o qual essa forma seria obtida, o que nos permitiria traduzi-la em português por formação". Bildung vem para o português como expressão, a grosso modo, de "formação cultural", que seria um aperfeiçoamento de potencialidades. A palavra "formação" tem grande reconhecimento nas obras de Kant, que discute a respeito do esclarecimento, colocando o homem como o próprio "culpado" pela menoridade. Segundo a sua teoria, o homem precisa estar sempre tutelado, não por falta de entendimento, mas por não querer 
tomar decisões, devido à falta de coragem.

Os pensamentos de Kant têm grande relevância na educação. Ao tratar da formação como forma de crescimento dos indivíduos, tambémtrazàluzumasociedademaisesclarecida, fazendo o uso da razão e se tornando sujeitos emancipados. Adorno faz de Kant um referencial.

Adorno faz uma crítica referente à formação cultural, pois acreditava que o sujeito estava passando por um empobrecimento, devido ao grande descaso pela formação. Para ele, o processo que deveria aperfeiçoar o sujeito para ser autônomo não passou de uma mercadoria formadora de sujeitos à determinada classe social. Em uma conversa com Becker, em Educação e Emancipação, Adorno é questionado sobre o porquê da sua preocupação em alertar os educadores para uma determinação social e técnica, por via do esclarecimento:

Que filósofo alerta os educadores em relação ao deslumbramento geral, e em particular o relativo à educação, que ameaça o conteúdo ético do processo formativo em função de sua determinação social. Isto é, adverte contra os efeitos negativos de um processo educacional pautado meramente numa estratégia de "esclarecimento" da consciência, sem levar na devida conta a forma social em que a educação se concretiza como apropriação de conhecimentos técnicos. (BECKER apud ADORNO, 2005, p. 9).

A resposta a esse questionamento vem do próprio Adorno: "quanto mais a educação procura se fechar ao seu condicionamento social, tanto mais ela se converte em mera presa da situação social existente" (ADORNO, 2005 , p. 9). Para o autor, quanto mais se busca socializar as pessoas, mais há uma imposição de regras que, ao invés de esclarecerem o sujeito, barbarizam-no com instrumentos para torná-lo social. Como consequência, o sujeito se prende dentro dessa teia, torna-se presa da socialização. A partir dessa visão socializadora, a educação torna-se um instrumento primordial à barbárie. Adorno acredita que se criou uma sociedade de "ilustração", em que se seguem regras determinadas em papéis. Por essa razão, acredita que a educação e a cultura se transformam em instrumentos de doutrinação. É através de ambas que se consegue propagar a humanização, como o autor pondera: "é a situação do sonho de humanidade que torna o mundo humano, sonho que o próprio mundo sufoca com obstinação na humanidade" (ADORNO, 2005, p. 9).

Essas leituras e reflexões sobre a situação da formação dos professores no Brasil fizeram nos aprofundar no tema formação continuada e, especificamente, a apresentada pelo programa governamental PNAIC. É uma proposta recente que precisa ser questionada, discutida e comentada. Os perfis dos participantes foram como se segue:

Sujeito 1: Trabalha na rede municipal há dois anos. Viúva, 45 anos de idade. Graduada em Pedagogia. Atuou no $2 \underline{a}$ ano do Ensino fundamental em 2015 e no $1^{\mathrm{o}}$ ano em 2016.

Sujeito 2: Trabalha na rede municipal há cinco anos. Casada, 31 anos de idade. Graduada em Pedagogia. Atuou no $1^{\underline{O}}$ ano do Ensino fundamental em 2015 e no 3 o ano em 2016.

Sujeito 3: Trabalha na rede municipal há 12 anos. Casada, 44 anos de idade. Graduada em Pedagogia. Atuou no $2^{\mathrm{o}}$ ano do Ensino fundamental em 2015 e no 3o ano em 2016.

Sujeito 4: Trabalha na rede municipal há dois anos. Casada, 38 anos de idade. Graduada em Pedagogia. Atuou no $1^{\underline{o}}$ ano do Ensino fundamental em 2015 e no 2을 2016.

Durante a pesquisa, os professores, ao serem entrevistados e questionados sobre a proposta apresentada pelo PNAIC para a formação continuada dos mesmos, responderam que esta "irá salvá-los de todos os seus problemas". Que seguir as determinações impostas pelo programa é o melhor caminho. Veem a proposta do programa como a sustentação de suas ações, o que fica perceptível 
em suas falas. Ao ouvirmos essas respostas os questionamos sobre o significado de formação, ao que responderam: "Formação continuada... é um apoio que se dá ao professor na sua prática." (Sujeito 1). O Sujeito 2 expõe uma necessidade de algo mais, de complemento: "Eu entendo formação nada mais é do que uma... capacitação a mais, para que você tenha condições de estar atuando em determinada área de trabalho... é uma coisa a mais, ela vem sempre a acrescentar algo a mais na sua área de trabalho." (Sujeito 2). Percebemos que esses sujeitos não veem a formação como o desenvolvimento de suas próprias práticas. Consideram-na um suporte, algo que vem pronto e que tem que ser executado. Também a definem como uma "capacitação direcionada", ou seja, como pré-determinada, socializada. Adorno, na Teoria da Semicultura, acredita que:

\begin{abstract}
A formação cultural agora se converte em uma semiformação socializada, na onipresença do espírito alienado, que, segundo sua gênese e seu sentido, não antecede à formação cultural, mas a sucede. Deste modo, tudo fica aprisionado nas malhas da socialização. Nada fica intocado na natureza, mas, sua rusticidade - a velha ficção - preserva a vida e se reproduz de maneira ampliada. Símbolo de uma consciência que renunciou à autodeterminação, prende-se, de maneira obstinada, a elementos culturais aprovados. Sob seu malefício gravitam como algo decomposto que se orienta à barbárie. (ADORNO, 1996, p. 2).
\end{abstract}

Os professores creem que o que chega até eles, sendo aprovado pelo governo, é o melhor. Isso faz com que renunciem ao conhecimento já adquirido, para apoiar programas prontos, como se tudo que aprenderam com as suas práticas escolares devesse ser reservado ou substituído por aqueles pré-estabelecidos pelo governo ou pela escola. Constatamos tal posicionamento no seguinte depoimento:

Formação, para mim, no sentido do nosso trabalho, seria assim, trazer fórmulas novas de se ensinar os conteúdos que nós temos, a ser aplicado, porque os conteúdos, eles não mudam, porém os métodos mudam, tem que mudar e eu acho que essa mudança só vai acontecer através da formação. (Sujeito 3).

Os professores desejam algo que venha pronto, que somente seja reproduzido, deixando de lado todo conhecimento adquirido, para utilizar somente aquele que lhe é imposto. O sujeito deixa de lado, então, a busca pelo esclarecimento, que traria luz à sua formação, para assumir um papel de receptor, aquele que somente recebe e transmite. Adorno e Horkheimer, em Dialética do Esclarecimento, citam que o indivíduo desaparece diante do poder econômico, porém, eleva-se tanto o sujeito com bens materiais, que ele acredita estar provido de cultura: "Desaparecendo diante do aparelho a que serve, o indivíduo vê-se, ao mesmo tempo, melhor do que nunca provido por ele" (ADORNO; HORKHEIMER, 1991, p. 5). A formação torna-se uma transmissão de obrigações a serem repassadas: "É estar envolvido em algum assunto que vá preparar a pessoa para ele ser repassado" (Sujeito 4).

O sujeito esclarecido, como Adorno define, é aquele sujeito que sai da posição de medo e assume uma posição de senhor dos seus próprios pensamentos, ou seja, é aquele que progride intelectualmente. Se isso acontecesse, prevê o autor, seria a calamidade triunfal. Adorno e Horkheimer desprezam a crença de que os outros sabem o que eles não sabem, ou mesmo que eles sabem o que não sabem. O sujeito fica subordinado ao outro, que tem força sobre ele a ponto de fazê-lo acreditar que o que ele sabe, ou o que ele alcançou de esclarecimento, aquilo que ele conseguiu formar, não é conhecimento:

a credulidade, a aversão à dúvida, a temeridade no responder, o vangloriar-se com o saber, a timidez no contradizer, o agir por interesse, a preguiça nas investigações pessoais, o fetichismo verbal, o deter-se 
em conhecimentos parciais: isto e coisas semelhantes impediram um casamento feliz do entendimento humano com a natureza das coisas e o acasalaram, em vez disso, a conceitos vãos e experimentos erráticos; o fruto e a posteridade de tão gloriosa união pode-se facilmente imaginar. (ADORNO; HORKHEIMER, 1991, p. 7).

Os autores frisam que essas contradições, a busca por um conhecimento superficial e outros fatores não tão importantes, fazem com que o sujeito nunca tenha uma posição ou uma ideia que seja dele - torna-se um sujeito subjugado. Vemos isso quando questionamos os sujeitos se o PNAIC, programa oferecido pela Secretaria de Educação, contribuiu, auxiliou ou ampliou a sua formação docente. Segundo um dos sujeitos:

O que está me contribuindo bastante é a questão da avaliação, que é bem frisada no PNAIC, que não adianta só a gente dar sequência nas atividades, mas também é... é... a gente tem que aprender avaliar, pra ver como é que tá caminhando a nossa turma... a nossa prática né... pra ver... se não tiver dando resultado, temos que reavaliar. (Sujeito 1).

Em sua visão, somente o PNAIC irá ensinálo a avaliar. O que aprenderam até o presente momento sobre avaliação de nada valeu, pois se não houver resultado daquilo que foi pedido a ele, terá que refazer, como se o professor não soubesse avaliar - toda receita tem que dar certo; se não der, refaz-se. O professor conforma-se com a imposição de que ele nada sabe, e que é preciso ter uma sequência formulada por outros, para o sucesso das suas práticas. Para Adorno e Horkheimer, há uma conformidade no pensamento a ponto de o sujeito aceitar o que é imposto sem questionar:

Não apenas são as qualidades dissolvidas no pensamento, mas os homens são forçados a real conformidade. O preço dessa vantagem, que é a indiferença do mercado pela origem das pessoas que nele vêm trocar suas mercadorias, é pago por elas mesmas ao deixarem que suas possibilidades inatas sejam modeladas pela produção das mercadorias que se podem comprar no mercado. (ADORNO; HORKHEIMER, 1991, p. 10).

Vemos que as pessoas trocam seus conhecimentos por aquilo que é oferecido pelo mercado. São manipuladas por ele, reproduzindo conhecimentos "enlatados". Esse produto que o mercado oferece, que traz tudo pronto, faz com que o professor se torne refém dele, como observamos na fala do Sujeito 2:

Ele (PNAIC), contribuiu no sentido de como você vai organizar a sala, o cantinho da leitura, da matemática, nas atividades, assim porque... nos propiciou essa visão mais ampla de como organizar mesmo e até mesmo trabalhar com as crianças determinadas atividades e agora, este ano, foi em relação à avaliação também foi muito útil, muito importante, até mesmo como poder estar avaliando os nossos alunos, porque o primeiro ano eles (referindo-se aos alunos) não têm notas. Então... de que forma estar avaliando... porque você está todos os dias com seus alunos, você sabe o desenvolvimento deles, o conhecimento até onde ele vai, mas às vezes, na hora de avaliar, estar falando, eu tenho uma certa dificuldade, mas foi muito bom. (Sujeito 2).

Observando a fala anterior, percebemos que o professor se torna dependente desse molde. Até mesmo para organizar a sua sala de aula, precisa de orientação. O sujeito se perde quanto à questão de avaliar seu aluno, por não ter nota. Se não tem nota, não sabe avaliar. Torna-se, então, refém do PNAIC, que traz o modelo de avaliação, ensina como avaliar. Vemos que o sujeito nega o seu eu, sua aprendizagem como professor, sua formação como sujeito e profissional para acatar totalmente as determinações do PNAIC. Adorno e Horkheimer apresentam essa negação como um sacrifício. O sujeito nega totalmente a sua racionalização, deixando-se guiar pelos 
pensamentos de outros, transformando-os em racionalidade, permutando a negação de si pela aceitação da vontade do outro. Como são muitas as imposições determinadas por outros a que o sujeito se submete, ele acaba entrando em dilemas diariamente. Tem dúvidas sobre qual método usar, como agir em determinadas ações, de que maneira irá alfabetizar e até mesmo sobre até que ponto a criança percebe o que é brincadeira e o que é aprendizagem. Tais dúvidas impedem-no de compreender o que a escola realmente quer

Sim!!! Porque eu comecei a aprender diferentes métodos de... para ensinar, através da construção de jogos. Nem tudo dá para ser aplicado como eu falei, não dá para aplicar tudo, porém uma boa parte a gente consegue fazer, deixar um pouquinho o tradicional. Mas sempre vai ter aquela barreira de que a escola, ela tem que ter aquele tradicional, porque senão... ela não é bem compreendida e também em relação aos alunos, eu creio que é assim. O PNAIC é bom, é muito bom, porém, devido à imaturidade das crianças, elas podem compreender que ali seja só para brincar, e não para estudar. (Sujeito 3).

Com tantas contradições, o sujeito fica frustrado. Aquilo que the foi ensinado deixa-o confuso: ora o tradicional, depois o construtivismo, e outros programas - o professor acaba atordoado com tantas imposições. Evidencia-se, aí, o "mundo de idealidades", como Adorno e Horkheimer citam na Dialética do Esclarecimento, em que dialogam que o mundo está repleto de ideias cujos objetos deixam de ser introduzidos um a um, ou caso a caso, fazendo com que as pessoas conheçam partes de cada objeto, e não o inteiro. Esse sistema torna tudo muito artificial, pois o sujeito não conhece o todo, somente o superficial. Quando está se adaptando a um projeto de ensino, ele é retirado e substituído por algo novo. Vemos a frustração: "Em algumas coisas sim, não era o esperado por mim!" (Sujeito 4).
Questionamos os sujeitos se o PNAIC, juntamente com o apoio dos formadores oferecidos pela Secretaria de Educação, desfavoreceu, dificultou ou atravancou a sua formação docente, e de que maneira isso ocorreu. Observemos uma das respostas a tais questionamentos:

Dificultou não é o caso, a questão é... é a questão de tempo mesmo, acredito que é muita coisa para estudar, tem muitos encontros, fora as obrigações da escola, né, que a gente tem... é... Acho que o tempo é muito corrido, é muita coisa para ser estudada, muita tarefa, muito texto e, em contrapartida, nós temos as nossas obrigações da escola, né? (Sujeito 1).

O professor não acredita que a formação do PNAIC seja dificultosa, no início as formações eram realizadas em alguns dias da semana no período noturno, depois foram ampliadas para todos os sábados devido à grande quantidade de material a ser estudado. Porém, o professor reclama das muitas obrigatoriedades que $\mathrm{O}$ PNAIC impõe, do tempo que tem que se dedicar. Aquele tempo que seria dito livre, ou seja, para os seus afazeres longe das obrigações cotidianas, ele está dedicando à formação. O sujeito, mesmo cansado, cumpre a obrigatoriedade do sistema e participa das formações. Adorno, em seu texto Tempo Livre, salienta que o trabalhador é acorrentado ao oposto do que seria o seu tempo livre: "Nem em seu trabalho, nem em sua consciência dispõem de si mesmas com real liberdade" (ADORNO, 1995, p. 1). Ocasionalmente, o professor fica preso ao PNAIC, pois deve dedicar-se mesmo depois de cumprir a sua carga horária:

não... assim... a formação docente não, porque a dificuldade maior é você estar participando, porque no caso desse ano... porque você trabalha manhã e tarde, aí formação das seis às dez da noite, então a dificuldade recai no cansaço físico, mas não na docência em si!. (Sujeito 2). 
O sujeito culpa o cansaço físico pela dificuldade de estar na formação no período em que poderia estar descansando. Verificamos que o sujeito se torna subjugado ao PNAIC, pois dedica o seu tempo livre à formação. Notemos um tom de reclamação na fala do Sujeito 3, quanto à disponibilidade de tempo para as formações do PNAIC:

Em algum momento, sim!!! Porque quando nós tínhamos formações aos sábados dia inteiro, às vezes foi à noite e era realizado assim, de um dia para o outro, uma falta de comunicação assim, eu creio que foi assim... ele não foi bem elaborado... elaborado não... ele não foi bem - como que vamos colocar - ele não foi bem organizado. Porque eu creio que ele poderia ter utilizado as horas atividades como compensação para os professores que tiveram o curso durante a noite ou durante qualquer período, não fazer os professores cumprirem horário do PNAIC, horário de estudo e ainda cumprir a hora atividade na escola. Por isso, muitas vezes foi desgastante mesmo. (Sujeito 3).

O Sujeito 2 vê que o PNAIC desfavoreceu e dificultou na questão do tempo, pois a formação poderia ser disponibilizada nas horas atividades do professor. É nas suas horas atividades que o professor produz as tarefas exigidas pelo PNAIC. Mesmo sabendo que o seu tempo foi totalmente desorganizado, o sujeito não questiona, pois sabe que está obedecendo ao comando ou à ordem do sistema que, para "formar", precisa do tempo máximo da massa. Adorno e Horkheimer acreditam que esse sujeito se torna apenas um ator, cumprindo diferentes papéis, e que só conseguirá se reencontrar quando romper com o acordo de seus inimigos e se tiver coragem de romper com aquilo que é colocado como absoluto. Acrescentam que, se o sujeito enxergasse o que lhe é imposto, que nada mais é que a forma de alienar e fazer com que seja apenas um braço a mais para mover a grande máquina que sustenta o estado maior, que é alienador, ele "seria capaz de inverter a direção do espírito do progresso impiedoso, ainda que este estivesse em vias de atingir sua meta" (ADORNO; HORKHEIMER, 1991, p. 39). Porém, o que vemos é que a razão dominante exige sacrifícios inquestionáveis, sacrifícios que o sujeito acredita que por eles será beneficiado.

Como vimos, o professor sacrificou o seu tempo livre, acreditando que isso traria uma contribuição à sua formação ou algo para o seu próprio benefício. Como aponta Adorno em Educação e Emancipação:

Em sua configuração atual - e provavelmente há milênios - a sociedade não repousa em atração, em simpatia, como se supôs ideologicamente desde Aristóteles, mas na persecução dos próprios interesses frente aos interesses dos demais. Isto se sedimentou do modo mais profundo no caráter das pessoas. O que contradiz o impulso grupal da chamada Lonely Crowd, da massa solitária, na verdade constitui uma reação, um enturmarse de pessoas frias que não suportam a própria frieza, mas nada podem fazer para alterá-la. (ADORNO, 2005, p. 133).

O processo de formação continuada, como apreciamos, tornou-se uma tentativa de troca de interesses entre o professor e o formador. Por isso pedimos aos sujeitos que pontuassem as características mais importantes de uma formação continuada, para analisarmos quais os interesses na formação do PNAIC e se o que foi oferecido contribuiu com o que interessava ao professor. Uma das respostas foi:

Eu acredito que o que mais contribui para uma formação são essas atividades práticas, né... é... que auxilie... com atividades dinâmicas, coisas inovadoras... que as pessoas possam nos orientar... abrir um leque de informações... para a gente ver que não existe só aquilo que estamos habituados... então quem puder contribuir com alguma coisa diferente, é válido. (Sujeito 1).

O professor anseia por uma recompensa pelo seu esforço-qualquer coisa que lhes ofereça 
como forma de gratificação é válida. Outro fato importante, nessa fala, é a questão da busca do professor por algo que complemente a sua prática pedagógica e que saia da mesmice, que alcance o seu interesse. Nas palavras do Sujeito 2:

É.. são seminários, as atividades mais dinâmicas... palestras e vídeos nós temos... Então seriam aulas mais dinâmicas... aulas com profissionais que atuam na área que estão há mais tempo... Porque eu sou novata, então... as aulas dos anos anteriores, eu não pude assistir, eu não participei. Então, as oficinas pedagógicas eu não fiz. (Sujeito 2).

Esse sujeito, que participou da formação mais atualizada, continua reclamando que falta algo mais nessas formações. De maneira geral, então, os sujeitos não viram uma troca. As formações não alcançaram aquilo que buscavam. Há uma ausência no atendimento das necessidades do professor quanto à sua prática pedagógica. Percebemos que, na tentativa de trocas de interesses entre os formadores do PNAIC e os formandos, não houve um preenchimento dos interesses dos professores:

Seria um curso de metodologia, de ludicidade, oficina de leitura, oficina de artes. Porque do jeito que a formação continuada é feita no nosso município, não contribui nem favorece o melhor aproveitamento do PNAIC. O PNAIC não alcança as nossas necessidades, dentro do nosso município, não. (Sujeito 3).

É evidente a frustração dos professores. Além de não conseguirem alcançar os seus interesses, exige-se deles algo que eles têm dificuldades de concretizar:

Um curso de letramento. Então .... Porque como base... o PNAIC tem a base mesmo é a leitura que fixa lá... que fala que... é discutido a leitura dos alunos... então ter um suporte né, para passar para a gente justamente nessa dificuldade que o aluno tem em ler, em se adaptar nesse processo de leitura. Tem uns que têm conhecimento, tem uns que não... até mesmo um livro para ele manusear, talvez ele só vê na escola, em casa ele não tem. Então, dar esse suporte para o professor. (Sujeito 4).

O Sujeito 4, pelo seu depoimento, tinha a expectativa de que o PNAIC fosse abordar algo do seu interesse. O professor busca algo que compense o tempo despendido. As recompensas são variáveis. Há palestras com pessoas competentes nas áreas estudadas, outras sem tanto preparo. O professor deseja atividades que correspondam as suas reais necessidades em sala de aula. Tudo leva a crer que o Sujeito 4 não reclamou para o formador sobre os seus reais interesses ou sobre o fato de que o conteúdo aplicado não ia ao encontro das suas necessidades, pois o PNAIC mantinha esse formador em seus eventos. Cremos que esses sujeitos pensavam que, de alguma maneira, tinham que levar vantagem, pois estavam aplicando algo imposto a eles em sala e também estavam perdendo o seu tempo livre enquanto estavam nas formações. Adorno chama esse tipo de atitude de participação oportunista: "O que se chama de 'participação oportunista' era antes de mais nada interesse prático: perceber antes de tudo a sua própria vantagem e não dar com a língua nos dentes para não se prejudicar" (ADORNO, 2005, p. 133).

Os professores poderiam ter comunicado sobre essas necessidades aos formadores, mas resolveram não falar, seja por medo de repreensão ou por falta de oportunidade. Quando lhes perguntamos se foram consultados alguma vez sobre suas necessidades formativas como professor alfabetizador pelo PNAIC, responderam: "Sim, tem as meninas que são do PNAIC, elas estão sempre em contato com a gente para tirar dúvidas né... para ver a questão de preencher relatórios, de orientação em sala de aula mesmo, eéconstanteessavisita..." (Sujeito1).

Vemos que os formadores iam às salas para verem a questão mais burocrática do PNAIC. 
Refizemos a pergunta, para saber se o Sujeito 1 foi consultado sobre suas necessidades formativas. Assim respondeu: "Eu acho que diretamente, assim, particularmente não... vem um programa já colocado... e assim... específico, com a necessidade da minha turma... não." (Sujeito 1).

Os sujeitos 2 e 3 também foram bem categóricos ao expressarem que não foram consultados. Somente o Sujeito 4 informou que the pediram a opinião sobre as suas necessidades formativas: "Sim! Nas visitas até mesmo que elas faziam na escola!" (Sujeito 4).

Os sujeitos, na maioria, foram submetidos às vontades dos seus superiores. Não lhes foi perguntado sobre as suas necessidades, sobre o que precisavam em suas salas de aulas, ou de que maneira as formações serviriam para auxiliar na prática. Tal atitude coisifica o indivíduo, que se torna o produto de determinados órgãos.

\section{Considerações finais}

Nos escritos de Adorno, em Educação e Emancipação, mais precisamente quando trata da experiência formativa, ele propõe que se elabore o passado e critique o presente que está prejudicado:

Após Auschwitz, é preciso elaborar o passado e criticar o presente prejudicado, evitando que este perdure e, assim, que aquele se repita. Que filósofo alerta os educadores em relação ao deslumbramento geral, e em particular o relativo à educação, que ameaça o conteúdo ético do processo formativo em função de sua determinação social. Isto é, adverte contra os efeitos negativos de um processo educacional pautado meramente numa estratégia de "esclarecimento" da consciência, sem levar na devida conta a forma social em que a educação se concretiza como apropriação de conhecimentos técnicos. Parafraseando Adorno no último parágrafo da Mínima Moralia, quanto mais a educação procura se fechar ao seu condicionamento social, tanto mais ela se converte em mera presa da situação social existente. É a situação do "sonho de uma humanidade que torna o mundo humano, sonho que o próprio mundo sufoca com obstinação na humanidade"! O desenvolvimento da sociedade a partir da Ilustração, em que cabe importante papel à educação e formação cultural, conduziu inexoravelmente à barbárie. Ou, para dizer o mesmo pelo reverso: o próprio processo que impõe a barbárie aos homens ao mesmo tempo constitui a base de sua sobrevivência. Eis aqui o nó a ser desatado. (ADORNO, 2005, p. 9).

Há nesse parágrafo a preocupação por parte de Adorno quanto às determinações impostas na construção do processo formativo, dessa maneira o sujeito deixa de refletir aquilo que tem de conhecimento e passa a seguir aquilo que lhe foi apresentado; o sujeito se torna um instrumentoreprodutordedeterminaçõessociais.

Ao fim da pesquisa, constatamos que o eixo "Formação Continuada" do Programa Nacional pela Alfabetização na Idade Certa, na concepção dos professores, apresentou uma falha ao não questionar os professores sobre as suas necessidades formativas antes da implantação, porém eles aceitaram tudo sem se opor, com medo de sofrer retaliações. Isso se explica pelo totalitarismo da razão instrumental: para se proteger, o sujeito acaba aceitando as imposições do outro, ou seja "perde-se para se conservar".

Os professores entrevistados acreditam que quando seus supervisores vão investigar suas ações pedagógicas e perguntam sobre as suas dúvidas de como aplicar as atividades do PNAIC estão sendo questionados sobre as suas necessidades formativas. Sobre a formação, os sujeitos entrevistados acreditam que é somente uma ação que irá complementar a sua prática pedagógica, concepção que vai ao encontro do que Adorno chama de "totalitarismo da razão instrumental": torna-se algo que vem somente par suprir uma necessidade instantânea governamental. O sujeito recebe sem questionar, pois, precisa do trabalho; cumpre para não 
perder o emprego; outros cumprem as ordens para não serem julgados pelos demais, ou para não serem chamados de retrógrados.

Não há, na percepção dos professores, uma investigação das suas necessidades formativas. O PNAIC tornou-se, para eles, obrigatório e cansativo. Percebemos que há uma conformação por parte dos professores, que não têm voz para opinar sobre aquilo que precisam para o seu crescimento intelectual e pedagógico. Aceitam o que lhes é imposto; conformam-se e adaptam-se ao sistema. Tal situação pode ser comparada ao que Adorno pondera sobre a democracia alemã, aos moldes dos Estados Unidos:

Mas a democracia não se estabeleceu a ponto de constar da experiência das pessoas como se fosse um assunto próprio delas, de modo que elas compreendessem a si mesmas como sendo sujeitos dos processos políticos. Ela é apreendida como sendo um sistema entre outros, como se num cardápio escolhêssemos entre comunismo, democracia, fascismo ou monarquia; ela não é apreendida como identificando-se ao próprio povo, como expressão de sua emancipação. Ela e avaliada conforme o sucesso ou o insucesso, de que participam também os interesses individuais, mas não como sendo a unidade entre os interesses individuais e o interesse geral; e, de fato, a delegação parlamentar da vontade popular torna esta muitas vezes uma questão difícil nos modernos Estados de massa. (ADORNO, 2005, p. 34).

Adorno expõe que as pessoas não conhecem o que é uma democracia. Creem que se trata somente de política; não percebem que são personagens essenciais para a sua construção. Isso acontece com o PNAIC ou com outros programas implantados pelo governo. Os sujeitos aceitam o programa que está em voga, porém se esquecem de que são peçaschave para o desenvolvimento da sua formação pedagógica, deixam de questionar e seguem o que foi lhe dito. Sendo assim, ao invés de formar professores críticos, temos uma classe que se volta às imposições governamentais que desconsidera todo o conhecimento já conquistado.

Concluímos que a formação precisa ser repensada de maneira que venha atender as necessidades do professor e não fazer dele somente um instrumento de disseminação de programas governamentais.

Em suma, consideramos que os professores necessitam romper com a barreira da imposição. Precisam ser autônomos o suficiente para decidir que direção querem tomar para construir a sua formação intelectual. A barbárie, imposta aos professores todos os dias, gera pessoas alienadas e distantes da emancipação.

\section{Referências}

ADORNO, T. W. Educação e emancipação. São Paulo: Paz e Terra, 2005. 190 p.

. Theodor W. Teoria da Semicultura. Tradução de Newton Ramos-de-Oliveira, Bruno Pucci

e Cláudia B. M. de Abreu. Educação e Sociedade, Campinas, n. 56, ano XVII, dez. 1996, p. 388411.

Tempo livre. In:

Palavras e sinais: modelos críticos 2. Tradução de Maria Helena Ruschel. Petrópolis: Vozes, 1995. p. 70-82.

ADORNO, T. W.; HORKHEIMER, M. Dialética do esclarecimento: fragmentos filosóficos. 2. ed. Rio de Janeiro: J. Zahar, 1991. 224 p.

BANDEIRA, H. M. M. Formação de professores e prática reflexiva. 2006. Disponível em: < http:// 
www.ufpi.br/subsiteFiles/ppged/arquivos/files/eventos/2006.gt1/GT1_13_2006.PDF>. Acesso em: 15 dez. 2017.

BRASIL. Ministério da Educação. Base Nacional Comum Curricular. MEC. Brasília, DF, 2017 b.

. Pacto Nacional pela Alfabetização na Idade Certa. Ministério da Educação Portaria no 826, de 7 de julho de 2017a. Dispõe sobre o Pacto Nacional pela Alfabetização na Idade Certa - PNAIC, suas ações, diretrizes gerais e a ação de formação no âmbito do Programa Novo Mais Educação PNME. Diário Oficial da União, Brasília, DF, 10 jul. 2017. Seção 1, p. 20.

Pacto Nacional pela Alfabetização pela Idade Certa. Portaria no 867, de 4 de julho de 2012. Disponível em: < http://pacto.mec.gov.br/images/pdf/port_867_040712.pdf>. Acesso em: 19 dez. 2017.

Secretaria de Educação Básica. Diretoria de Apoio à Gestão Educacional. Pacto Nacional pela Alfabetização na Idade Certa: Apresentação. Brasília, DF: MEC, 2015. 72 p.

EVANGELISTA, E. G. S. Razão instrumental e indústria cultural. Inter-Ação: Revista da Faculdade de Educação, Goiânia, v. 28, n. 1, p. 83-101, jan./jun. 2003.

MARTINS, G. A. Estudo de caso: uma reflexão sobre a aplicabilidade em pesquisas no Brasil RCO. Revista de Contabilidade e Organizações, São Paulo, v. 2, n. 2, p. 8-18 jan./abr. 2008. Disponível em: <http://www.revistas.usp.br/rco/article/view/34702/37440>. Acesso em: 28 out. 2017.

PUCCI, B. Teoria crítica e educação. In: Teoria crítica e educação: a questão da formação cultural na Escola de Frankfurt. Petrópolis: Vozes, 1994. p. 11-15.

SILVA, D. O. Lógica dialética e crítica à razão instrumental: a teoria crítica de Max Horkheimer. Dissertação (Mestrado em Filosofia) - Faculdade de Filosofia e Ciências Humanas, Universidade Federal de Minas Gerais, Belo Horizonte, 2015.

Submetido em 22 de dezembro de 2017.

Aprovado em 4 de abril de 2018. 